\title{
McConnell's sign: an early and specific indicator of acute pulmonary embolism
}

\author{
Soumya Patra, Ravi S Math, Ravindranath K Shankarappa, Navin Agrawal
}

Department of Cardiology, Sri Jayadeva Institute of Cardiovascular Sciences \& Research, Bangalore, Karnataka, India

\section{Correspondence to} Dr Navin Agrawal,

drnavinagrawal@gmail.com

Accepted 11 February 2014

\section{DESCRIPTION}

A 76-year-old woman was admitted with acute onset of breathlessness with lethargy since the last 3 days. She was a known patient with hypertension and diabetes. On clinical examination, she had an engorged neck vein, tachycardia and tachypnoea, hypotension, oxygen saturation of $92 \%$ in room air and right ventricular S3 gallop with pansystolic murmur in the left lower parasternal area. ECG showed sinus tachycardia with an S1Q3T3 pattern. Chest X-ray did not reveal any significant abnormality. There was no elevation of cardiac biomarkers. Echocardiography revealed the presence of right atrial and ventricular dilation, moderate tricuspid regurgitation, severe right ventricular dysfunction, regional wall motion abnormality of the basal and mid right ventricular free wall with apical hyper contractility (McConnell's sign), paradoxical septal motion and dilated inferior vena cava (figure 1A-C; videos $1-3$ ). The CT pulmonary angiogram was suggestive of acute pulmonary embolism (APE) (figure 2). She was treated with infusion of streptokinase for $48 \mathrm{~h}$, followed by an oral anticoagulant.

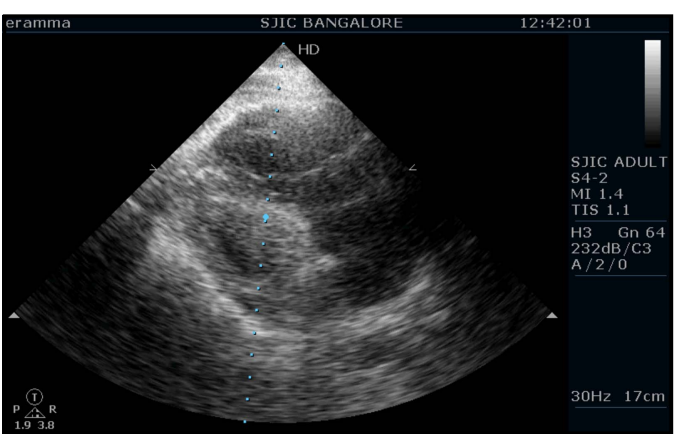

Video 1 Paradoxical long axis view demonstrated dilated right atrium \& ventricle with hyper contractile right ventricular apex with left ventricle.

McConnell's sign is the most distinct echocardiographic finding described in patients with APE. ${ }^{1}$ There is a regional pattern of right ventricular dysfunction, with akinesia of the mid free wall and hyper contractility of the apical wall. ${ }^{1}$ McConnell's sign is considered as a specific sign of APE. ${ }^{2}$ Though echocardiography has poor sensitivity, it

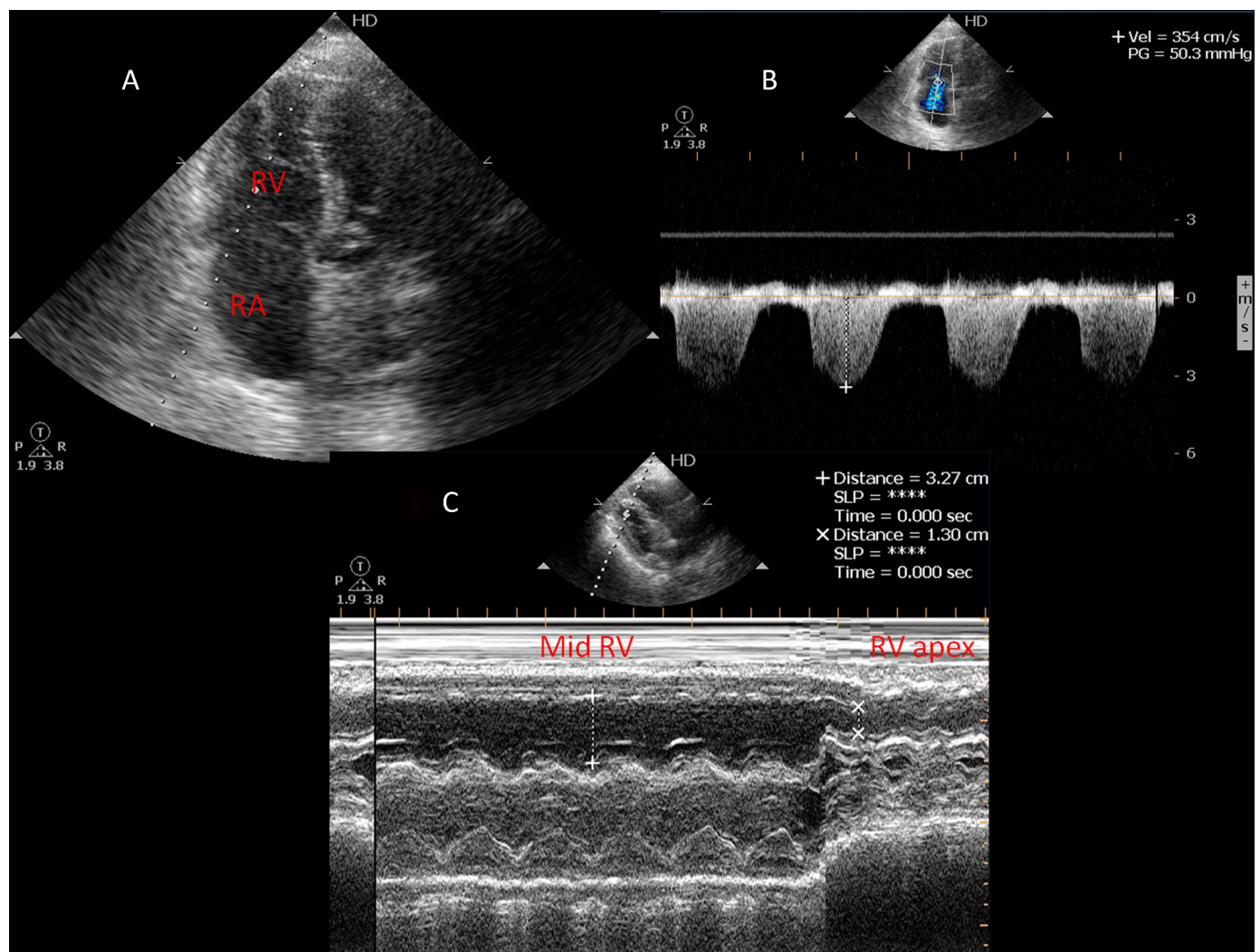

Figure 1 (A-C) Echocardiography revealed a dilated right atrium and ventricle, moderate tricuspid regurgitation and M-mode echocardiography revealed an akinetic mid-right ventricular free wall with a hyper contractile right ventricular apex (McConnell's sign). 


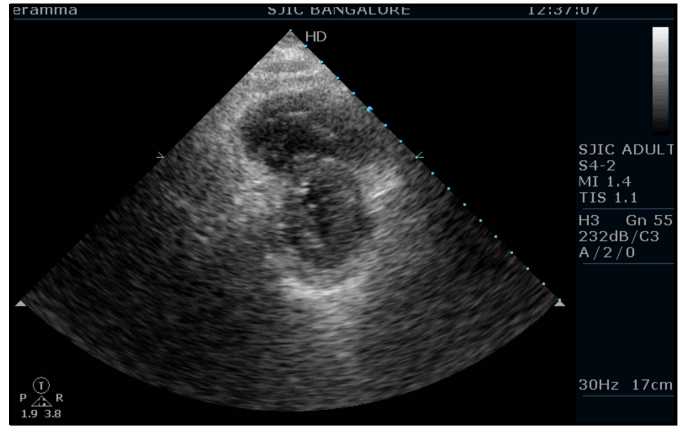

Video 2 Parasternal short axis view showed paradoxical septal motion.

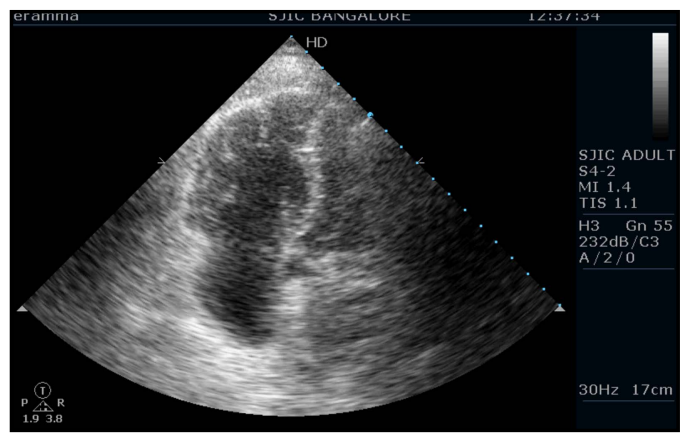

Video 3 Apical 4-C view showed dilated right atrium \& ventricle with regional wall motion abnormality of right ventricular free wall at mid \& basal segment with apical hyper contractility.

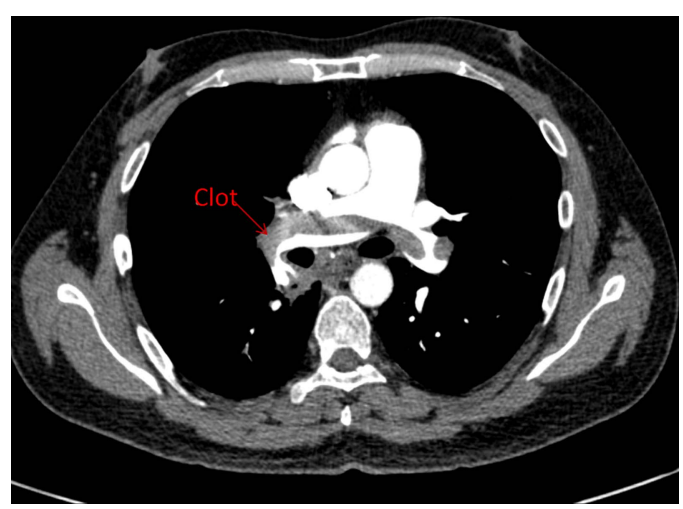

Figure 2 CT pulmonary angiogram revealing the features of acute pulmonary embolism. may be useful in cases of massive pulmonary embolism in which a rapid presumptive diagnosis is required to justify the use of thrombolytic therapy.

\section{Learning points}

- McConnell's sign is a distinct echocardiographic feature of acute massive pulmonary embolism.

- It is defined as a regional pattern of right ventricular dysfunction, with akinesia of the mid free wall and hyper contractility of the apical wall.

- In a case of acute pulmonary embolism, we should try to elicit this echocardiographic sign and if it is seen, then thrombolytic therapy should be started.

Contributors SP, RSM, RKS and NA were involved in the management of the patient.

Competing interests None.

Patient consent Obtained.

Provenance and peer review Not commissioned; externally peer reviewed.

\section{REFERENCES}

1 Grifoni S, Olivotto I, Cecchini P, et al. Short-term clinical outcome of patients with acute pulmonary embolism, normal blood pressure, and echocardiographic right ventricular dysfunction. Circulation 2000;101:2817-22.

2 López-Candales A, Edelman K, Candales MD. Right ventricular apical contractility in acute pulmonary embolism: the McConnell sign revisited. Echocardiography 2010;27:614-20.

Copyright 2014 BMJ Publishing Group. All rights reserved. For permission to reuse any of this content visit

http://group.bmj.com/group/rights-licensing/permissions.

BMJ Case Report Fellows may re-use this article for personal use and teaching without any further permission.

Become a Fellow of BMJ Case Reports today and you can:

- Submit as many cases as you like

- Enjoy fast sympathetic peer review and rapid publication of accepted articles

- Access all the published articles

- Re-use any of the published material for personal use and teaching without further permission

For information on Institutional Fellowships contact consortiasales@bmjgroup.com

Visit casereports.bmj.com for more articles like this and to become a Fellow 